\title{
İnsansız Su Altı Aracındaki İtici Motorda Kullanılması Planlanan Bir Pervanenin Serbest Titreșim Karakteristiğinin İncelenmesi
}

\author{
Talha Gülgün ${ }^{*}$, İsmail Yalçınkaya², Mertcan Erdoğdu ${ }^{3}$, Akif Durdu $^{4}$ \\ ${ }^{1 *}$ Konya Teknik Üniversitesi, Mühendislik ve Doğa Bilimleri Fakültesi, Makine Mühendisliği Bölümü, Konya, Türkiye, (ORCID: 0000-0003-4896-8611), \\ talhagulgunn@gmail.com \\ ${ }^{2}$ Konya Teknik Üniversitesi, Mühendislik ve Doğa Bilimleri Fakültesi, Makine Mühendisliği Bölümü, Konya, Türkiye (ORCID: 0000-0002-6567-399X), \\ ismailyalcinkaya96@gmail.com \\ ${ }^{3}$ Konya Teknik Üniversitesi, Mühendislik ve Doğa Bilimleri Fakültesi, Makine Mühendisliği Bölümü, Konya, Türkiye (ORCID: 0000-0003-4613-8729), \\ mrtcn7899@gmail.com \\ ${ }^{4}$ Konya Teknik Üniversitesi, Mühendislik ve Doğa Bilimleri Fakültesi, Elektrik Elektronik Mühendisliği Bölümü, Konya, Türkiye, (ORCID: 0000-0002-5611-2322), \\ adurdu@ktun.edu.tr
}

(İlk Geliş Tarihi 16 Ekim 2021 ve Kabul Tarihi 29 Aralık 2021)

(DOI: $10.31590 /$ ejosat.1010720)

ATIF/REFERENCE: Gülgün, T., Yalçınkaya, İ., Erdoğdu, M. \& Durdu, A. (2021). İnsansız Su Altı Aracındaki İtici Motorda Kullanılması Planlanan Bir Pervanenin Serbest Titreşim Karakteristiğinin İncelenmesi. Avrupa Bilim ve Teknoloji Dergisi, (31), 870873.

Öz

Kendi kendini yönetebilen insansız araçlara; sanayi, sağlık sektörü, savunma sanayi gibi birçok sektörde, insan gücünün kullanılmasının tehlikeli veya imkânsız olduğu durumlarda ihtiyaç giderek artmıştır. İnsansız sualtı araçları, üzerinde herhangi bir operatöre ihtiyaç duymadan çeşitli sualtı görevlerini yerine getirebilen sualtı robotlarıdır. Robot kol, kamera gibi araçlar ile görevlerde daha aktif rol oynamak için donatılmış olabilirler. Göreve bağlı olarak, araca monte edilen sensörler ile birlikte de hassas sonuçlar elde ederek görevde başarı oranı artırılabilmektedir. Bununla birlikte, insansız sualtı araçlarının tümü, otonom seviyesi ne olursa olsun ülkelerin sualtı misyonları için önemli bir rol oynamaktadır. İnsansız sualtı araçlarının en önemli sistemlerinden bir tanesi de itki sistemidir. Pervane sistemleri ise su altı ve su üstü araçların sevk edilmesinde yararlanılan önemli bir itki sistemi elemanıdır. Kullanım alanına göre farklı niteliklerde olabilmektedir. Kullanılan pervane, görevleri istenilen performansta uygulanabilir şekilde olması ve yakıt tüketimini düşürmesinin yanı sıra kontrollü bir seyrin sağlanabilmesi adına da çok önemli olmaktadır. Bu çalışmada, insansız sualtı aracı itki sistemi elamanı olan pervanenin serbest titreşim frekansı araştırılarak, çalışma aralığında rezonansla karşılaşabilme ihtimali incelenecektir. PLA malzemesinde imal edilen pervane, ANSYS programı structural analysis modülünde maksimum çalışma devri göz önünde bulundurularak bir ön gerilmeye tabi tutulmuştur. Ardından modal modülünde ise çalışma devri sonucu meydana gelen titreşim frekansı, serbest titreşim frekansıyla karşılaştırılıp rezonans durumu incelenmiştir.

Anahtar Kelimeler: İnsansız Su Altı Aracı, İtki Sistemi, Pervane, Rezonans, Serbest Titreşim Karakteristiği.

\section{Investigation of the Free Vibration Characteristic of a Propeller Planned for Use in a Thruster in an Unmanned Underwater Vehicle}

\begin{abstract}
The need for self-driving unmanned vehicles has increased in many sectors such as industry, health sector, defense industry, where the use of manpower is dangerous or impossible. Unmanned underwater vehicles are underwater robots that can perform various underwater tasks without the need for any operators on them. They can be equipped to play a more active role in tasks with tools such as a robotic arm, camera. Depending on the task, the success rate of the task can be increased by achieving precise results together with the sensors installed in the vehicle. However, all unmanned underwater vehicles, regardless of their autonomous level, play an important role for countries ' underwater missions. One of the most important systems of unmanned underwater vehicles is the propulsion system. Propeller systems, on the other hand, are an important element of the propulsion system that is used in the dispatch of underwater and above-water vehicles. It may have different qualities depending on the area of use. The propeller used is very important for its tasks to be applicable at the desired performance and to reduce fuel consumption, as well as to ensure a controlled course. In this thesis, the free vibration frequency of the unmanned underwater vehicle propeller, which is the propulsion system element, will be investigated. And the possibility of experiencing resonance during the study will be examined. Manufactured in PLA material, the propeller was subjected to a pre-stress in the structural analysis module of the ANSYS program, taking into account the maximum operating speed. Then, in the modal module, the frequency of vibration consisting of the working cycle was compared with the frequency of free vibration and the resonance state was examined.
\end{abstract}

Keywords: Free Vibration Characteristic, Propulsion System, Propeller, Resonance, Unmanned Underwater Vehicle.

\footnotetext{
*Sorumlu Yazar: talhagulgunn@gmail.com
} 


\section{Giriş}

İnsansız su altı araçları, boyut ve işlev olarak, sadece izleme amaçlı su altı kameraları vasıtasıyla görüntü almaya ve bazı ölçümler yapmaya yönelik, nispeten küçük ve basit araçlar olabileceği gibi, üzerlerinde yer alacak pek çok sensör, kamera, sonar vb. yardımıyla büyük oranda otonom çalışma yetkinliğine sahip, manipülatörler kullanarak oldukça karmaşık işlevleri yerine getiren büyük sistemler de olabilmektedir (Budiyono, 2009; Canlı et al.; Cevheri, 2009; Gülgün et al., 2020).

Özellikle iş sınıfı insansız su altı aracı olarak adlandırılan, aslen insansız su altı iş makineleri olarak düşünülebilecek olan araçlar, $250 \mathrm{~m}$ ile sınırlı olan insanlı dalışların kısıtlarını ve tehlikelerini bertaraf etmekte, 3000 m' yi aşan derinliklerde çok zor bir takım inşa, bakım görevlerini yerine getirebilmektedir (Boehm et al., 2018; Canlı et al.; Kumar et al., 2018; Gülgün et al., 2020).

Küçük ve basit araçlardan, iş sınıfı insansız su altı aracı olarak adlandırılan araçlara kadar olan tüm robotlarda ise itki sisteminin elamanı olan pervaneler oldukça önem taşımaktadır. Pervaneler su altı ve su üstü taşıtlarının yönlendirilmesinde yararlanılan, araçlara istenilen hareket ve yol alma olanağı tanıyan itki elemanları olup kullanıldıkları yerlere göre birçok çeşitleri bulunmaktadır. Bazı sistemlerde sessizlik isteri ön planda tutulurken, bazı durumlarda hızlı manevra veya yüksek h1z isterleri öncelikli olabilmektedir (Canlı et al.).

Pervane tasarımının istenilen işlevi yerine getirebilmesi için tasarım süreci çok önemlidir. Yakıt tüketiminin en az düzeye çekilebilmesi, taşıt sistemi manevralarının istenilen düzeyde olması doğru bir pervane tasarımı sonucunda gerçekleşebilmektedir. Pervane tasarımı için başvurulan birçok yöntem olmakla birlikte, pervane beceri ve veriminin yükseltilmesi öncelikli hedeflerden bazılarıdır.

$\mathrm{Bu}$ çalışmada; arama-kurtarma, keşif vb. görevlerde kullanıma uygun insansız su altı aracında kullanılması planlanan bir pervanenin serbest titreşim karakteristiği incelenecek olup çalışma sırasında rezonans durumu araştırılacaktır.

\section{Materyal ve Metot}

Mühendislikte kullanılan elemanların statik ve dinamik kuvvetlere maruz kaldıklarında, bu kuvvetlere verecekleri tepkiler oldukça önemlidir. $\mathrm{Bu}$ tepkilerin incelenmesi için öncelikle serbest titreşim karakteristiklerinin öğrenilmesi gerekmektedir. Serbest titreşim karakteristiğinin öğrenilmesi, yapının hangi titreşim frekansında hangi mod şekliyle karşılaşacağının öğrenilmesi anlamına gelmektedir. Yapının maruz kaldığı kuvvetlerin frekansı ile serbest titreşim frekanslarının karşılaştırılması ise rezonans olayı açısından önemli olacaktır (Şekerci, 2013).

Yapının denge konumu etrafında tekrarlanması titreşim hareketi olarak tanımlanabilmektedir. Dinamik yükler etkisinde çalışan sistemlerde de tekrarlı bir hareket olan titreşim hareketi meydana gelmektedir. Mekanik titreşimler, mühendislik yapılarının birçoğunda önemli problemleri açığa çıkarabilmektedir. Uzun süreli titreşimler makine elemanının yorulmasına neden olabileceği gibi yüksek genlikteki titreşimler de hasar ve kirılmalara neden olabilmektedir. $\mathrm{Bu}$ nedenle endüstride kullanılan birçok yapının dinamik yükler etkisi altında nasıl bir davranış gösterdiği, sistemin güvenli bir şekilde e-ISSN: 2148-2683 çalışması ve performansı açısından oldukça önemlidir. Bu amaçla incelenen yapının doğal frekansları, yapısal sönümü ve titreşim biçimleri elde edilerek gerekli dinamik analizler yapılmalıdır (Alarcin et al., 2012; Güngör, 2013; Kumar et al., 2018).

Titreşim analizinin yapılması ile yapının doğal titreşim frekansları bulunmuş olur. Yapıya uygulanan periyodik bir kuvvetin frekans1, bu doğal frekanslardan herhangi birisi civarında ise, bu frekans uyarılmış olur ve yapı bu doğal frekans ve şekli ile titreşmeye başlar. Eğer uyarıcı kuvvetin frekansı ile yapının doğal frekansı çakışır ise "rezonans" olayı meydana gelir (Er, 1998).

Rezonans, dinamik bir kuvvet etkisinde zorlanmış titreşimler yapan bir yapının doğal frekansı ile zorlamanın frekansının eşit olmasına sebep olmaktadır. Bu durumda yapının titreşim genliği artma eğilimine girmektedir. $\mathrm{Bu}$ genlik artışı sistemin düzgün çalışmasını engellediği gibi, onun hasara uğramasına da neden olabilmektedir (Er, 1998).

Deniz araçlarında aracın kontrolü ve idamesinin sağlanması amacıyla itki sistemi kullanılır ve çoğunlukla pervaneler itki sistemi içerisinde kritik rol oynar (Hara et al., 2011; Vardhan et al., 2019). Gemi, denizaltı, insanlı - insansız sualtı araçları olarak sıralanabilen deniz araçlarında çoğunlukla pervane malzemesi gelenekselleşen yöntem olarak belirtilebilecek nikel alüminyum bronz (NAB) ve mangan alüminyum bronz (MAB) alaşımları kullanılmaktadır. $\mathrm{Bu}$ malzemelerin kullanılmasının avantajlarının bulunmasının yanı sira dezavantajları da bulunmaktadır. Malzeme maliyetinin düşük, yüksek rijitlik, akma dayanımının yüksek ve korozyona karşı yüksek direnç göstermeleri avantajları olarak gösterilmektedir. Pervane biçiminden dolayı yüksek işleme maliyeti, üretim aşamasının uzun olması, çalışma esnasında ses oluşumuna neden olması ve titreşim özelliği göstermesi ise dezavantajları olarak gösterilmektedir. Pervanelerde kullanılabilecek alternatif malzemeler olarak ise paslanmaz çelik, titanyum alaşımı ve kompozit malzemeler gösterilebilir. (Mouritz et al., 2001; Samsul; Vardhan et al., 2019).

Araştırmada kullanılan pervanenin malzemesi pla flament olarak seçilmiştir. $\mathrm{Bu}$ malzeme seçilmesinin nedeni üzerinde kullanılacak olan insansız su altı aracının boyut ve ağırlık bakımından küçük olmasıdır. PLA Flament malzemesi kullanılarak 3 boyutlu yazıcı yardımıyla düşük maliyete ve kısa sürede temin edilmesinin yanı sıra istenilen pervane biçimi verilmiş ve fazla ağırlıktan kaçınılmıştır.

Sualtı görevlerinde kullanılmak üzere özgün su altı aracı ve pervane tasarımı gerçekleştirilmiştir. Araçta kullanılan motor pervanelerinin analizi sonlu elemanlar yöntemi kullanılarak Ansys programında gerçekleştirilmiştir. Programda pervanenin yapısal davranışını incelemek, ayrıca ön gerilme değeri eklemek amacıyla static structural modülü kullanılmıştır. Ön gerilme sonucu oluşan kuvvetle birlikte meydana gelen titreşim karakteristiğini görmek için modal modülü static structural modülüne bağlanmış ve modal analiz sonucu ortaya çıkan sonuçlar incelenmiştir.

Pervaneler ilk olarak ön gerilme yükleme amacıyla statik analize tabi tutulmuş olup ardından modal analiz ile serbest titreşim karakteristiği incelemiştir. Ön gerilme olarak 3600 rpm rotasyonel hız değeri olarak analize tanımlanmıştır. Girilen değer, araçta kullanılan firçasız motorun planlanan maksimum çalışma devirdir. Modal analize aktarılan bu girdiden başka 
hiçbir girdi kullanılmamış, sadece rotasyon kuvvetinden meydana gelebilecek titreşimler araştırılmıştır. Modal analizde 6 adet mod durumu çözdürülmüştür. Ansys programında varsayılan olarak karşımıza gelen bu 6 adet mod miktarı çalışmanın sonuçlarını görebilmek bakımından yeterliliğine karar verilmiştir.

\section{Araştırma Sonuçları ve Tartışma}

Modal analizde çözdürülen modlardan kritik olanı ilk moddur ve değeri 846,56 Hz'dir. İlk modun kritik olmasının nedeni ise ilk modda oluşan değerin yapının rezonansa girdiği andaki değer olmasıdır. Pervaneye gelen 6 adet mod değerleri Tablo 1'de gösterilmiştir.

Tablo 1. Oluşan mod değerleri

\begin{tabular}{|c|c|}
\hline Mode & Frequency $(\mathbf{H z})$ \\
\hline 1 & 846,56 \\
\hline 2 & 870,63 \\
\hline 3 & 895,53 \\
\hline 4 & 2168,9 \\
\hline 5 & 2198,4 \\
\hline 6 & 2308,4 \\
\hline
\end{tabular}

$\mathrm{Bu}$ modların pervanede oluşturduğu etkileri daha iyi anlamak için frekans olan değerlerin devire (rpm'e) dönüştürülmesi yararlı olacaktır. Denklem 1'de kritik olan ilk mod durumundaki hertz değerinin $\mathrm{rpm}$ değerine dönüşümü gösterilmiştir.

$$
\begin{aligned}
& 1 \text { Hertz }=60 R P M \\
& R P M=60 \times 846,56
\end{aligned}
$$

Rezonans anındaki RPM değeri $=50793,6$

Hesaplama sonucunda iticide kullanılan pervane 50793,6 devire ulaştığı zaman rezonansa girip pervane yapısına bozulmalar meydana gelecektir. 50793,6 değeri planlanan çalışma değeri olan 3600 devirin çok üzerinde olduğundan dolayı pervanenin çalışma aralığında rezonans durumu görülmemiştir. Rezonans durumunun olmadığ gözlemlenmişsede 3600 devirde çalıştırılan pervanenin bu devirde plastik deformasyona uğrayıp uğramayacağı da incelenmiştir. İncelemeye devam edilmesinin nedeni, yapının rezonansa uğramadan önce malzeme özelliklerinden dolayı akmaya uğrama ihtimali olmasıdır. Static structural modülünde yapısal karakteristikleri çözdürülen pervanenin, oluşan deformasyon değeri Şekil 1'de, pervanede meydana gelen stres değeri ise Şekil 2'de gösterilmiştir.

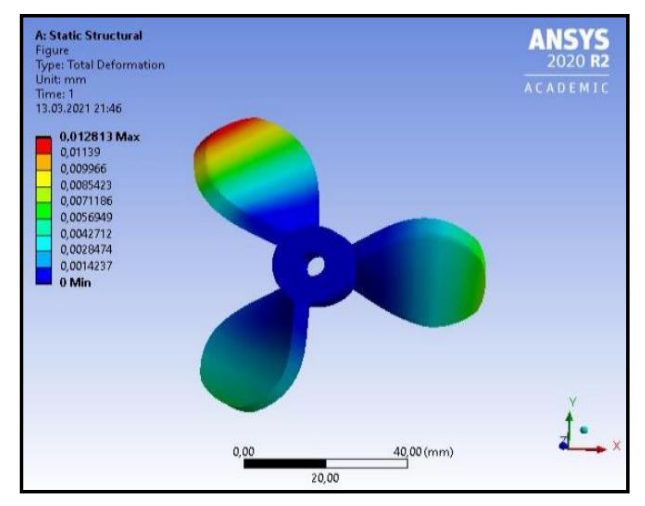

Şekil 1. Pervanede oluşan deformasyon miktarl e-ISSN: 2148-2683

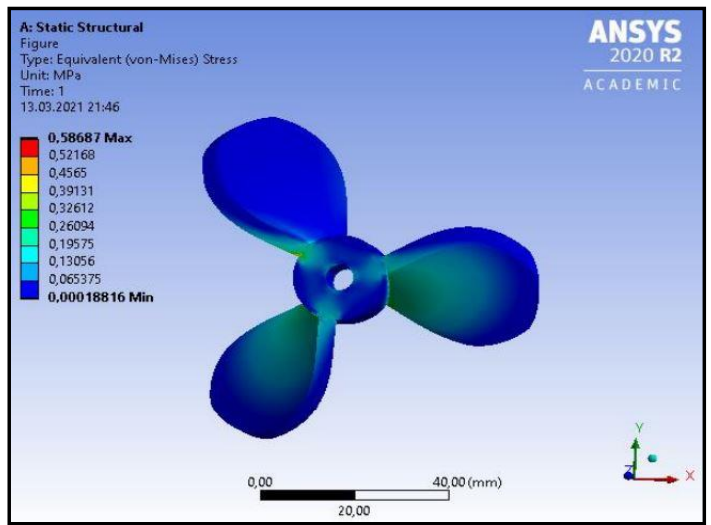

Şekil 2. Pervanede oluşan stres miktart

Pervanede meydana gelen maksimum stres değeri 0,58 $\mathrm{N} / \mathrm{mm}(\mathrm{MPa})$, pervanede kullanılan PLA malzemesinin akma mukavemeti ise $70 \mathrm{~N} / \mathrm{mm}(\mathrm{MPa})$ dir. Oluşan maksimum stres değeri, akma mukavemetinin altında olduğundan dolayı pervanenin deformasyona uğramayacağı gözlemlenmiştir. Deformasyon miktarı açısından inceleniğinde de yapı için herhagi bir problem teşkil etmemektedir.

Şüphesiz ki titreşim karakteristiğinin tasarım sürecinde incelenmesi zaman ve maliyet açısından avantaj sağladığ görülmektedir. Rezonans durumuna rastlanması sonucunda meydana gelebilecek yüksek deformasyon miktarı da bunu desteklemektedir.

Kullanılan pervanelerin rezonans anında sergileyeceği tepki incelenmek istenmiş ve rezonansa girdiği değer olan 50793,6 devirde analiz tekrar çözdürülmüştür. Rezonans durumunun oluşması ile ortaya çıkan deformasyon miktarı Şekil 3'te gösterilmiştir.

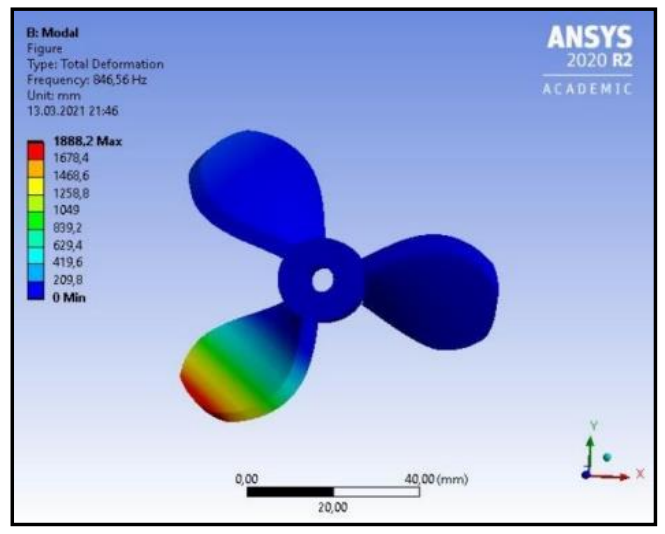

Şekil 3. Rezonans anında oluşan yer değiştirme miktarı

Şekil 3'te görüldüğü üzere rezonans anında oluşan yer değiştirme miktarı 1888,2 mm hesaplanarak oldukça yüksek miktara erişmiştir.

Rezonans anında oluşan yer değiştirme miktarı ile maksimum çalışma devrinde oluşan yer değiştirme miktarı karşılaştırıldığında; rezonans anında oluşan yer değiştirme miktarının 147365,95 kat daha büyük olduğu görülmektedir. Bir yapının rezonansa girdiği zaman oluşan yer değiştirme miktarının, normal çalışma zamanlarında oluşan yer değiştirme miktarlarının çok çok üzerinde çıkacağı bilinmektedir. Yapılan bu modal analiz sonucunda oluşan ilk frekans değerinin, mod 
değerinin, bu kadar büyük bir değer çıkması çözdürülen analizi doğrular niteliktedir.

Bu çalışmadan elde edilecek sonuçlar, mühendislik alanında bilime hizmet etmek isteyen mühendis ve mühendis adayları tarafından kullanılabilme özelliğine sahiptir. $\mathrm{Su}$ altı sistemlerinde kullanılmak üzere tasarlanacak olan insanlı insansız su altı araçlarının, üzerlerinde bulunan itici motorların önemli bir parçası olan pervane tasarımı aşamasında yapının serbest titreşim karakteristiğinin incelenmesi konusunda yol gösterici durumda bulunmaktadır. Tasarlanan yapının çalışma aralığında rezonansa girip girmeyeceği, hangi çalışma aralığında rezonansa gireceği ve rezonans anında yapının sergileyeceği karakter hakkında okuyucuya bilgi sahibi edinmesini sağlayacaktır.

\section{Sonuç}

Arama-kurtarma, keşif vb. görevlerde kullanılabilecek insansız su altı aracında, itici motorda kullanılması için tasarlanan bir pervanenin serbest titreşim karakteristiği Ansys programı yardımı ile elde edilmiştir. Yine Ansys programı yardımı ile pervaneye etki eden kuvvetin meydana getirdiği titreşim frekans değeri de elde edilmiştir.

Elde edilen bu değerler karşılaştırılmış ve rezonans durumundaki çalışma devrinin, planlanan çalışma devrinin çok üzerinde oluşması yapının rezonansa uğramayacağı anlamına gelmektedir. Ansys programı kullanılarak belirli bir açısal hız ile çalışan pervanenin deformasyona uğrayıp uğramadığı kontrol edilmiştir. Sonuç olarak; yapılan tüm incelemelerin ardından insansız sualtı aracında kullanılacak olan pervanede herhangi bir olumsuz sonuca rastlanmamıştır ve pervanenin çalışma aralığında sorunsuz bir şekilde görevlerini yerine getireceği anlaşılmıştır.

\section{Teșekkür}

$\mathrm{Bu}$ çalışmanın yürütülmesi sırasında yardımlarını esirgemeyen Sayın Konya Teknik Üniversitesi Rektörü Prof. Dr. Babür Özçelik'e, aracın üretimi sırasında sponsorluk anlamında desteklerini esirgemeyen Robotik Otomasyon ve Kontrol Laboratuvarı (rac-lab.com)'na, T3 Vakfına, Kapsül Teknoloji Platformu'na; bu çalışmanın ortaya çıkmasında emeği geçen tüm saygıdeğer hocalarımıza ve personele bizlere verdikleri sonsuz desteklerinden dolayı teşekkürü borç biliriz.

\section{Kaynakça}

Alarcin, F., \& Korkmaz, F. C. (2012). Vibration analysis of ship main engine and shaft system. Journal of Engineering and Natural Sciences, Sigma, 3, 310-319.

Boehm, J., Berkenpas, E., Henning, B., Rodriguez, M., Shepard, C., \& Turchik, A. (2018). Characterization, modeling, and simulation of an ROV thruster using a six degree-of-freedom load cell. Paper presented at the OCEANS 2018 MTS/IEEE Charleston.

Budiyono, A. (2009). Advances in unmanned underwater vehicles technologies: Modeling, control and guidance perspectives.

CANLI, G. A., kurtoğlu, İ., Canlı, M. O., \& Tuna, Ö. S. Dünyada ve ülkemizde insansız sualtı araçları isaa-auv \& rov tasarm ve uygulamalarl. Gidb dergi(04), 43-75.
Cevheri, N. (2009). Computer aided engineering of an unmanned underwater vehicle.

Er, Y. (1998). Gemi pervanelerine etkileyen hidrodinamik yüklerin bulunması ve gerilme analizinin yapılması.

Gülgün, T., Alankaya, G., Duran, M. E., Erdoğdu, M., DURDU, A., YALÇINKAYA, İ. s., \& Terzioğlu, H. (2020). Analysis of the Effect on the Thrust Force as a Result of Positioning Thrusters at Different Angles in Underwater Vehicles in CAD Environment. Avrupa Bilim ve Teknoloji Dergisi, 357362.

Gülgün, T., Alankaya, G., Duran, M. E., Erdoğdu, M., Yalçinkaya, İ., Durdu, A., \& Terzioğlu, H. (2020). Low-Cost Unmanned Underwater Vehicle Design. Avrupa Bilim ve Teknoloji Dergisi, 363-367.

Güngör, E. (2013). Hesaplamalı Akışkanlar Dinamiği Kullanılarak Su Altı Araçları İçin Pervane Tasarımı Ve Analizi. Fen Bilimleri Enstitüsü.

Hara, Y., Yamatogi, T., Murayama, H., Uzawa, K., \& Kageyama, K. (2011). Performance evaluation of composite marine propeller for a fishing boat by fluid-structure interaction analysis. Paper presented at the 18th international conference on composite materials, Jeju Island, Korea.

Kumar, G. S., Painumgal, U. V., Kumar, M. C., \& Rajesh, K. (2018). Autonomous underwater vehicle for vision based tracking. Procedia computer science, 133, 169-180.

Mouritz, A. P., Gellert, E., Burchill, P., \& Challis, K. (2001). Review of advanced composite structures for naval ships and submarines. Composite structures, 53(1), 21-42.

Samsul, B. Structural Analysis of a Composite Marine Propeller by Finite Element Method.

Şekerci, H. U. (2013). Bir Hava Aracı Komponentinin Dinamik Karakteristiklerinin Teorik Ve Deneysel Modal Analiz Metoduyla Belirlenmesi. Fen Bilimleri Enstitüsü.

Vardhan, D. H., Ramesh, A., \& Reddy, B. C. M. (2019). A review on materials used for marine propellers. Materials Today: Proceedings, 18, 4482-4490. 